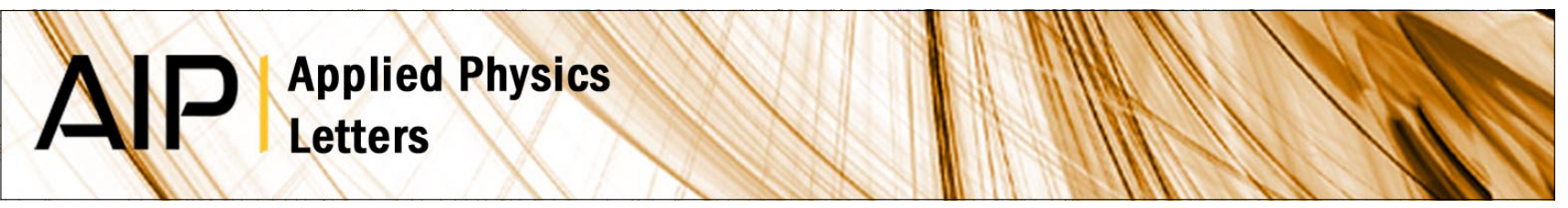

\title{
Structures and physiological functions of silica bodies in the epidermis of rice plants
}

Shigeru Yamanaka, Hiroyuki Takeda, Satoshi Komatsubara, Fuyu Ito, Hisanao Usami et al.

Citation: Appl. Phys. Lett. 95, 123703 (2009); doi: 10.1063/1.3232204

View online: http://dx.doi.org/10.1063/1.3232204

View Table of Contents: http://apl.aip.org/resource/1/APPLAB/v95/i12

Published by the American Institute of Physics.

\section{Related Articles}

Electronic, structural, and elastic properties of metal nitrides $\mathrm{XN}(\mathrm{X}=\mathrm{Sc}, \mathrm{Y})$ : A first principle study AlP Advances 2, 032163 (2012)

Magnetic tri-axial grain alignment in misfit-layered bismuth-based cobaltites

J. Appl. Phys. 112, 043913 (2012)

Room-temperature structures of solid hydrogen at high pressures

J. Chem. Phys. 137, 074501 (2012)

Secondary phase Cu2SnSe3 vs. kesterite Cu2ZnSnSe4: Similarities and differences in lattice vibration modes J. Appl. Phys. 112, 033719 (2012)

High pressure ionic and molecular crystals of ammonia monohydrate within density functional theory

J. Chem. Phys. 137, 064506 (2012)

\section{Additional information on Appl. Phys. Lett.}

Journal Homepage: http://apl.aip.org/

Journal Information: http://apl.aip.org/about/about_the_journal

Top downloads: http://apl.aip.org/features/most_downloaded

Information for Authors: http://apl.aip.org/authors

\section{ADVERTISEMENT}

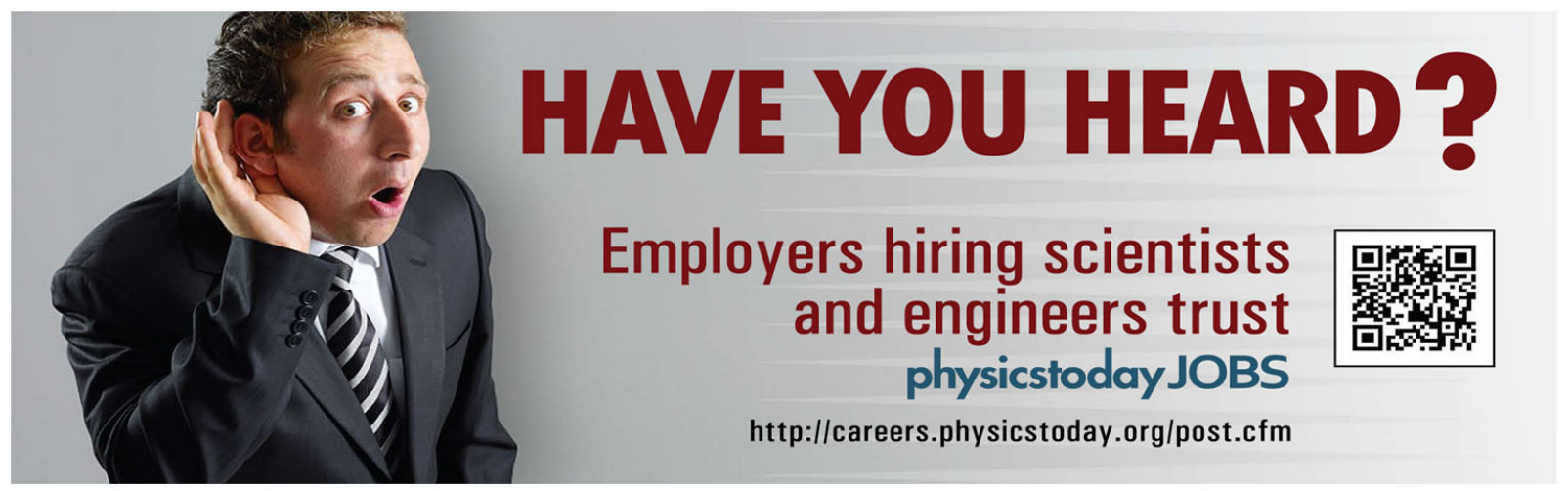




\title{
Structures and physiological functions of silica bodies in the epidermis of rice plants
}

\author{
Shigeru Yamanaka, ${ }^{1, a)}$ Hiroyuki Takeda, ${ }^{2}$ Satoshi Komatsubara, ${ }^{3}$ Fuyu Ito, ${ }^{1}$ \\ Hisanao Usami, ${ }^{1,4}$ Eiji Togawa, ${ }^{5}$ and Katsumi Yoshino ${ }^{3,6,7}$ \\ ${ }^{1}$ Collaborative Innovation Center for Nanotech FIBER (nanoFIC), Shinshu University, 3-15-1 Tokida Ueda, \\ Nagano 386-8567, Japan \\ ${ }^{2}$ Department of Physics, University of Toronto, 60 St. George St., Toronto, Ontario M5S 1A7, Canada \\ ${ }^{3}$ Shimane Institute for Industrial Technology, 1 Hokuryo-cho, Matsue, Shimane 690-0816, Japan \\ ${ }^{4}$ Faculty of Textile Science and Technology, Shinshu University, 3-15-1 Tokida Ueda, \\ Nagano 386-8567, Japan \\ ${ }^{5}$ Forestry and Forest Products Research Institute, 1 Matsunosato Tsukuba 305-8687, Japan \\ ${ }^{6}$ Collaboration Center, Shimane University, 2 Hokuryo-cho, Matsue, Shimane 690-0816, Japan \\ ${ }^{7}$ Innovation Center for Advanced Science, Osaka University, 2-1 Yamadaoka, Suita, Osaka 565-0871, Japan
}

(Received 11 July 2009; accepted 28 August 2009; published online 24 September 2009)

\begin{abstract}
We characterized silica structures in the epidermis of rice plant leaves and investigated their physiological functions from optical and mechanical viewpoints. By treating the distribution of silica bodies as a triangular lattice in the $x y$ plane, and performing a theoretical optical analysis on this lattice, we discovered that a reduction in the photonic density of states may inhibit leaves of rice plant from being heated markedly higher than $20^{\circ} \mathrm{C}$. Ladderlike structures in the epidermis were mechanically investigated. These structures are conjectured to inhibit flat leaves from undergoing twisting torsions, which may assist the leaf to absorb sunlight more effectively for photosynthesis. @ 2009 American Institute of Physics. [doi:10.1063/1.3232204]
\end{abstract}

Biomineralization is a naturally occurring process by which living organisms form skeletons from inorganic minerals such as silica and calcium. Structures made from biosilica are constructed either on cell surfaces or within unicellular organisms (e.g., diatoms ${ }^{1}$ and radiolaria) and certain cells in multicellular sponges ${ }^{2}$ and plants. ${ }^{3,4}$ These structures have been found to exhibit physiological functions in addition to maintaining the cell shape. For example, diatom frustules enable diatoms to withstand high pressures ${ }^{5}$ and their intricate nanostructures were found to play a role in regulating light absorption, functioning like photonic crystals by reducing excessive levels of blue light and thereby enhancing photosynthesis. ${ }^{6}$

Some species of the grass Oryzae, including Oryza sativa, are well known as silicon-accumulating plants that produce rice. Silica has been reported to benefit rice plants by increasing their resistance to certain micro-organisms. ${ }^{7}$ It has been speculated that silica structures provide support for the leaf. Thus, we decided to analyze the functions of silica structures in rice plants by utilizing recent developments in nanotechnology. In rice plants, various arrangements of silica bodies are found in the epidermis. These arrangements are fundamentally similar, although they do exhibit minor variations among the various species of Oryza. ${ }^{8}$

Leaves of a rice plant (Oryza sativa L., cv. Hinohikari) were harvested at various stages of cultivation (i.e., from saplings, mature plants, and harvestable plants) from paddy fields in Osaka, Japan. We focused our investigation on silica bodies and ladderlike silica structures on the assumption that the former structures are related to light absorption whereas the latter affect the mechanical properties.

\footnotetext{
${ }^{\text {a) }}$ Author to whom correspondence should be addressed. Electronic mail: syamana@ytv.home.ne.jp.
}

In field-emission scanning electron microscopy observations (SEM) (S-5000, Hitachi), various structures were identified in the leaves, including cubic bodies, ladderlike structures, trichomes (fine outgrowths or appendages on plants), and stomas (Fig. 1). Essentially identical structures were found on both sides of the leaves, regardless of the stage of cultivation. Energy-dispersive x-ray analysis (Emax Energy, Horiba) revealed cubic silica bodies ${ }^{9}$ and ladderlike structures, as well as other silicon-containing structures, indicating the presence of silica.

Although the silica bodies seen in Fig. 1 appear to be randomly distributed in the epidermis of the rice plant, the distance between adjacent bodies is almost constant. For simplicity, we consider that they occupy a two-dimensional (2D) triangular lattice in the $x y$ plane of the epidermis. From Fig. 1, we estimated that the average lattice constant is $a$ $=5.6 \mu \mathrm{m}$, radius of the grains is $R=1 \mu \mathrm{m}$, and refractive index of the grains is $n=1.46$. The ambient gas is air.

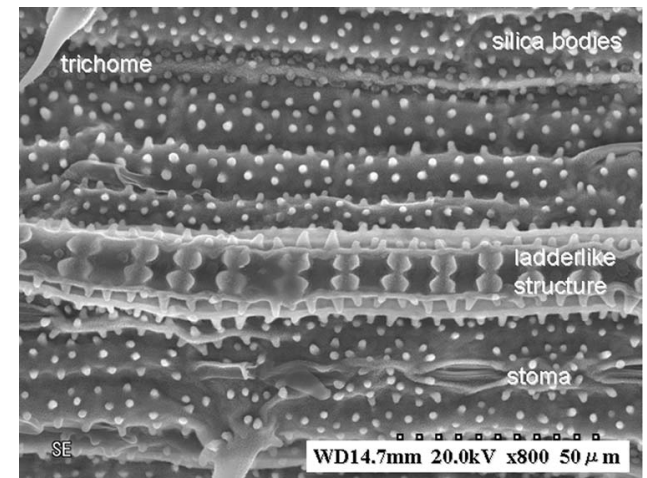

FIG. 1. SEM image of epidermal region of a rice plant leaf. There are two kinds of silica bodies observed: small scattered bodies and bodies sandwiched between two walls. The latter resemble ladders (hence, they are referred to as ladderlike structures). 


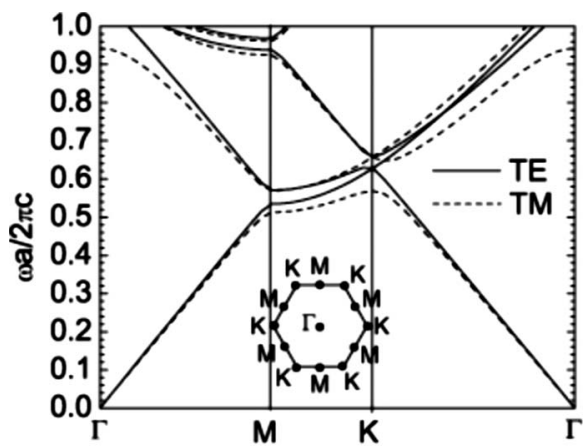

(a)

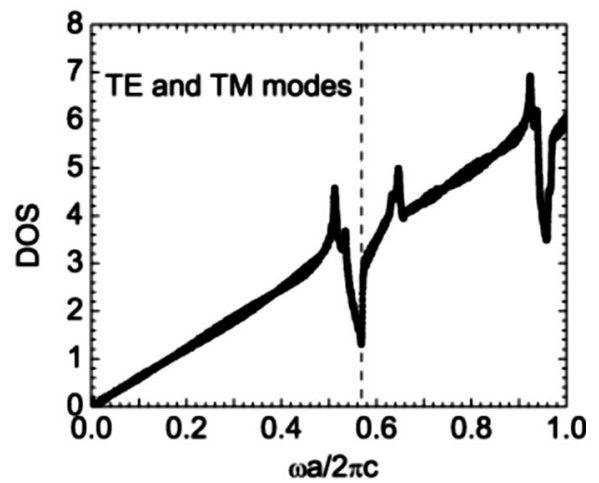

(b)

FIG. 2. (a) Photonic band structure of the 2D triangular-lattice photonic crystal. The vertical and horizontal axes indicate the angular frequency and wave vector, respectively. The solid and dashed lines indicate the TE and TM modes, respectively. The electric fields in the TE and TM modes are parallel and perpendicular to the $x y$ plane, respectively. The hexagonal inset indicates the first Brillouin zone of the $2 \mathrm{D}$ triangular lattices. The points $\Gamma$, $M$, and $K$ are symmetry points in the first Brillouin zone. (b) Photonic density of states for TE and TM modes. The photonic DOS decreases dramatically at $\omega a / 2 \pi c=0.568$ (indicated by the dashed line).

The photonic band structure of the 2D triangular-lattice photonic crystal is shown in Fig. 2(a). The vertical and horizontal axes indicate the angular frequency and the wave vector, respectively. The solid and dashed lines represent the transverse electric (TE) and transverse magnetic (TM) modes, respectively. In the TE and TM modes, the electric fields are parallel and perpendicular to the $x y$ plane, respectively. The hexagonal inset indicates the first Brillouin zone of the 2D triangular lattice, and the points $\Gamma, M$, and $K$ are symmetry points within this zone. For example, the $\Gamma-M$ direction signifies that light propagates in one of the six directions between $( \pm \sqrt{3} / 2, \pm 1 / 2)$ and $(0, \pm 1)$ in the $x y$ plane. Similarly, the $\Gamma-K$ direction implies that light propagates in one of the six directions between $( \pm 1 / 2, \pm \sqrt{3} / 2)$ and $( \pm 1,0)$. As shown in Fig. 2(a), in the frequency region $0.5 \leq \omega a / 2 \pi c \leq 0.6$, there are photonic bandgaps in certain light propagation directions (pseudophotonic bandgaps).

To confirm the efficiency of the pseudophotonic bandgaps, we investigated the photonic density of states (DOS). The DOS is the number of states at each frequency level and it is defined by

$$
\rho(\omega)=\frac{v}{(2 \pi)^{d}} \sum_{n} \int_{B . Z .} d^{d} \mathbf{k} \delta\left(\omega-\omega_{n \mathbf{k}}\right),
$$

where $n$ is the photonic band number, $\boldsymbol{k}$ is the wave vector, $v$ is the volume of the unit cell, and $d(=2)$ is its dimension. The

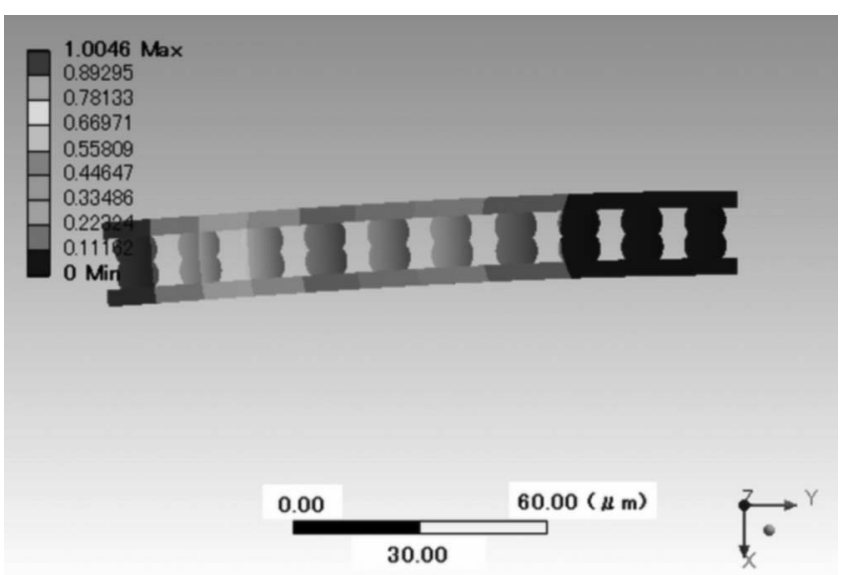

FIG. 3. Deformation diagram of a ladderlike structure after a forced displacement of $1 \mu \mathrm{m}$ was applied in the plane of the leaf.

photonic DOS for both the TE and TM modes are shown in Fig. 2(b), and can be seen to decrease dramatically at $\omega a / 2 \pi c=0.568$ (indicated by the dashed line). This frequency corresponds to a wavelength of $\lambda=9.86 \mu \mathrm{m}$ (since $\omega a / 2 \pi c=a / \lambda$ ). Absorption of electromagnetic waves strongly depends on the photonic DOS. In other words, we expect to find a reduction in the absorption of electromagnetic radiation in rice plants at $\lambda=9.86 \mu \mathrm{m}$. Infrared radiation with a wavelength of $10 \mu \mathrm{m}$ corresponds to the peak of a black body curve at a temperature of $20{ }^{\circ} \mathrm{C}$. Therefore, this reduction in the photonic DOS at $\lambda=9.86 \mu \mathrm{m}$ may inhibit leaves of rice plants from being heated markedly higher than $20{ }^{\circ} \mathrm{C}$.

Experiments on creeping bentgrass leaves revealed that biosilicified tissue in epidermal cells reduces the temperature of the leaves via emission of mid-infrared radiation. ${ }^{10} \mathrm{Al}-$ though these results are similar to the results of the theoretical optical analysis, the optical mechanism has yet to be clarified.

Next, we analyzed the function of the ladderlike silica structures shown in Fig. 1. One possibility is that they cause mechanical strengthening of the thin leaf. With this in mind, the flexural rigidity of such structures was evaluated by structural analysis (ANSYS) based on the finite element method.

The deformation diagram obtained when a forced displacement of $1 \mu \mathrm{m}$ was applied in the plane of the leaf is shown in Fig. 3. The reaction force was calculated to be approximately $94 \mu \mathrm{N}$. Likewise, the deformation diagram was obtained when a forced displacement of $1 \mu \mathrm{m}$ was applied perpendicular to the plane of a leaf. In this case, the reaction force was calculated to be approximately $1.4 \mu \mathrm{N}$. Thus, the flexural rigidity is about 70 times higher in the plane of the leaf than perpendicular to it. This suggests that the ladderlike structures inhibit the flat leaf from undergoing twisting torsions, which may assist the leaf to absorb sunlight more effectively. It should also be mentioned that from the above analysis, the flexural rigidity perpendicular to the plane of the leaf was found to increase with increasing silica content.

This work was supported by "Innovation Creative Center for Advanced Interdisciplinary Research Areas (Shinshu University)" Project in Special Coordination Funds for Promoting Science and Technology of the Ministry of Educa- 
tion, Culture, Sports, Science, and Technology, the Japanese Government (Grant No. 300012). We express our sincere thanks to Mr. Muneharu Kitano of Kishiwada, Osaka for supplying the rice leaves from their paddy fields, and to Dr. N. Hayashida, Dr. M. Kimura, and Dr. M. Ohguchi of Textile Science and Technology, Shinshu University for discussions in the field of plant science and chemistry.

${ }^{1}$ M. Sumper and N. Kröger, J. Mater. Chem. 14, 2059 (2004).

${ }^{2}$ W. E. G. Müller, J. Li, H. C. Schröder, L. Qiao, and X. Wang, Biogeosciences 4, 219 (2007).
${ }^{3}$ H. A. Currie and C. C. Perry, Ann. Bot. (London) 100, 1383 (2007),

${ }^{4}$ M. Laue, G. Hause, D. Dietrich, and B. Wielage, Mikrochim. Acta 156, 103 (2007).

${ }^{5}$ C. E. Hamm, R. Merkel, O. Springer, P. Jurkojc, C. Maler, K. Prechtel, and V. Smetacek, Nature (London) 421, 841 (2003).

${ }^{6}$ S. Yamanaka, R. Yano, H. Usami, N. Hayashida, M. Ohguchi, H. Takeda, and K. Yoshino, J. Appl. Phys. 103, 074701 (2008).

${ }^{7}$ S. Yoshida, Y. Ohnishi, and K. Kitagishi, Soil Sci. Plant Nutr. 8, 1 (1962).

${ }^{8}$ S. S. Whang, K. Kim, and W. M. Hess, Am. J. Bot. 85, 461 (1998).

${ }^{9}$ S. Agarie, W. Agata, H. Uchida, F. Kubota, and P. B. Kaufman, J. Exp. Bot. 47, 655 (1996).

${ }^{10}$ L. Wang, Q. Nie, M. Li, F. Zhang, J. Zhuang, W. Yang, T. Li, and Y. Wang, Appl. Phys. Lett. 87, 194105 (2005). 